\title{
Delivering on the promise of cancer biomarkers in the clinic
}

\author{
Jane de Lartigue, $\mathrm{PhD}$
}

ancer is still the second leading cause of death in the United States and earlier diagnosis and effective therapies remain the holy grail of research paradigms. Cancer biomarkers have emerged as an invaluable tool in the achievement of this goal. Technological advancements and greater understanding of the molecular mechanisms of cancer have transformed biomarker research from an observational byproduct of cancer research into a biomedical research field in its own right. Despite the explosion of biomarker discovery over the last decade, few have been translated into clinical use. Here we discuss the current state of biomarker development and the challenges that have tempered their clinical potential.

\section{Exploiting the unique cancer cell signature}

Cancer continues to be a major cause of morbidity and mortality; in 2014, there will be an estimated 1.6 million new cases of cancer and more than half a million cancer-related deaths. ${ }^{1}$ As such, there remains a pressing need for earlier diagnosis and improved treatment options.

Biomarkers are defined by the National Institutes of Health as "any characteristic that can be objectively measured and evaluated as an indicator of normal biological processes, pathogenic processes or pharmacologic responses to a therapeutic intervention." They have long been used as indicators of various disease states, and cancer is no exception. The first cancer biomarker, identified in the mid1800s, was the immunoglobulin light chain, found in the urine of myeloma patients. ${ }^{3}$ Since then, a variety of hormones, enzymes, and other proteins have been observed at altered concentrations in the biological fluids of cancer patients and have proven useful as biomarkers indicative of the presence of cancer.

Over the past several decades, significant technological advances and greater understanding of the molecular mechanisms underlying the development of cancer have led to the realization that the signature molecular alterations that drive the pro- cess of carcinogenesis are also an important source of potential cancer biomarkers (Figure 1). The result has been an explosion in cancer biomarker discovery and, although early discoveries were based primarily on empirical observations of single markers, there has been a shift toward large-scale analyses of multiple markers and the development of a multidisciplinary biomedical research field.

\section{The promise of cancer biomarkers}

As the field of cancer biomarkers has developed into its own entity, the potential clinical utility of biomarkers has likewise evolved giving rise to numerous types of cancer biomarkers (Table 1). A fairly comprehensive, though not exhaustive, list of biomarkers that are used in clinical practice and their approved uses is shown in Table 2. The vast majority of these biomarkers are protein-based, however, biomarkers encompass a wide range of different molecules, including deoxyribonucleic acid (DNA), messenger ribonucleic acid (mRNA), metabolites, and even whole cells.

\section{Screening/diagnostic}

Diagnostic markers can be present at any stage of cancer development and are designed to assist in providing a definitive diagnosis. Typically, cancer is diagnosed by examining the morphology of cells present in a biopsied tissue sample. Identifying variations in the levels of cancer biomarkers in biological fluids supplements the diagnosis by indirect characterization of the tumor. For example, in prostate cancer, increased levels of prostate specific antigen (PSA) in the blood, in combination with other clinical characteristics, are used to aid in diagnosis and staging. ${ }^{4,5}$

Recent advancements in high throughput genomic, proteomic, and even metabolomic technologies has driven the identification of DNA, RNA, protein, and metabolite biomarkers that are potentially informative in the diagnosis of cancer. Use of next-generation sequencing technologies can be particularly useful in establishing a diagnosis in metastatic tumors, for which there is frequent ambi-

JCSO 2014;12:381-388. @2014 Frontline Medical Communications. DOI 10.12788/jcso.0082. 


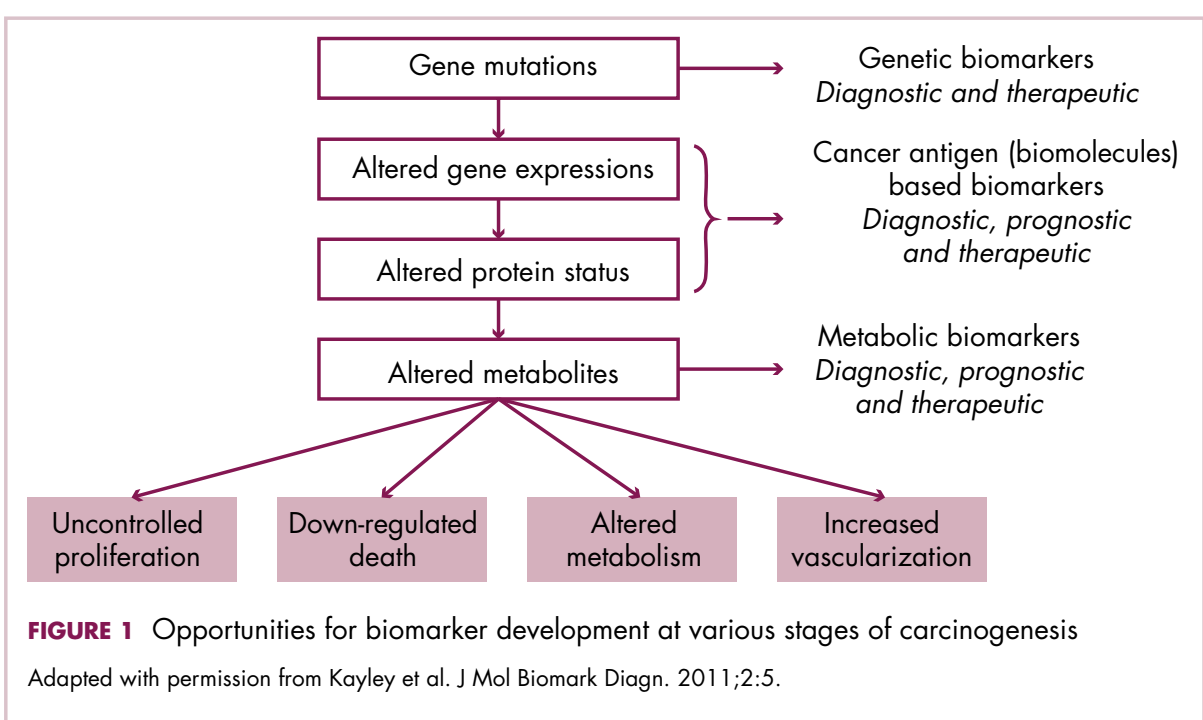

markers are useful in determining the aggressiveness of the cancer type and predicting patient outcomes irrespective of treatment. A key example is the human epidermal growth factor receptor 2 (HER2) protein; high levels of HER2 expression are found on up to $20 \%$ of breast cancers and it is associated with increased tumor aggressiveness and reduced survival..$^{8-10}$

There is an emerging realization that panels of biomarkers rather than single biomarkers will be required for biomarker assays to have sufficient sensitivity and specificity for diagnosis and prognosis. To this end, a number of multigene assays have been developed, some examples of which are shown in Table 3. The number of genes evaluated in these assays ranges from the single digits up to many hun-

guity. Each year in the US, between 90 and 130,000 newly diagnosed metastatic patients have an unclear diagnosis, many of which are so-called cancer of unknown primary. ${ }^{6}$ By comparing the gene expression profile of a metastatic tumor sample with a database of known tumor types or subtypes, a more definitive diagnosis can be made. This is the basis of the CancerTYPE ID tool, which has shown almost $90 \%$ accuracy in distinguishing the tissue of origin in metastatic patients with unclear diagnosis. ${ }^{7}$

A significant goal is the identification of biomarkers, known as screening biomarkers, that are indicative of early-stage cancers, to assist in a more timely diagnosis. Thus far, most diagnostic biomarkers do not have adequate sensitivity or specificity for screening. One exception is the human papillomavirus, which is present in more than $90 \%$ of patients with uterine and cervical cancers and has formed the basis of a nationwide cervical cancer screening program.

\section{Prognostic}

Once a cancer diagnosis has been made, prognostic bio- dreds. Perhaps best known are those used in breast cancer, such as the Oncotype DX test, which measures the expression of 21 breast cancer-associated genes in patients with ductal carcinoma in situ and invasive carcinoma to predict the likelihood of distant recurrence and the potential benefit of chemotherapy. Despite some controversy, the test has been incorporated into 3 major clinical guidelines in recent years. ${ }^{11,12}$

The most recently developed multigene assay is Prosigna, which determines the postsurgical risk of recurrence in patients with stage I/II node-negative or stage II nodepositive and hormone receptor-positive patients. It incorporates the PAM50 expression profile of 50 genes, which classify the tumors into 4 intrinsic subtypes. Researchers evaluating the test found that it provided more prognostic information than other methods and was better able to distinguish between intermediate and high-risk patients. ${ }^{13,14}$

\section{Predictive}

Predictive biomarkers have been intensely investigated

\section{TABLE 1 Types of biomarkers \\ Type}

Early detection/screening

Diagnostic

Disease monitoring

Risk assessment

Prognostic

Predictive

\section{Description}

Identifies cancer at an earlier stage than typical diagnostic methods Establishes a specific diagnosis

Assesses disease response during treatment, potentially allowing for adjustments

Provide a quantitative means to determine predisposition to a certain type of cancer

Determine the aggressiveness of the particular cancer and predict outcome independent of specific treatment

Predicts response to therapy and provides guidance in choice of therapy 
TABLE 2 Biomarkers used in clinical practice

\section{Biomarker}

Human epidermal growth factor receptor 2 protein overexpression or gene amplification

EGFR exon 19 deletion or L858R (exon 21 substitution) mutation

EGFR protein overexpression

Hormone receptor (estrogen receptor and progesterone receptor) expression

Philadelphia chromosome $(t[9 ; 22])$ positive; $B C R-A B L$

BCR-ABL T315I mutation

CD30 protein expression

KRAS codon 12 and 13 mutation

Anaplastic lymphoma kinase gene rearrangement

\section{BRAF V600E/K mutation}

\section{CD25 antigen expression}

CD20 antigen expression

c-KIT expression

Platelet-derived growth factor receptor B gene rearrangement

\section{Human papillomavirus}

HE-4

\section{CA- 125}

Transthyretin

\section{Apolipoprotein A-1}

Beta microglobulin

Transferrin

Fibrin/fibrinogen degradation product

Alpha-fetoprotein L3 (AFP-L3)

\section{Clinical use}

Assessment for ado-trastuzumab emtansine and lapatinib therapy in breast cancer and for pertuzumab and trastuzumab therapy in breast and gastric cancer

Assessment for afatinib and erlotinib therapy in NSCLC

Assessment for cetuximab and panitumumab therapy in CRC

Assessment for anastrazole, everolimus, exemestane, fulvestrant, letrozole, and tamoxifen therapy in breast cancer

Assessment for bosutinib, dasatinib, and nilotinib therapy in $\mathrm{CML}$, ponatinib therapy in $\mathrm{ALL}$, and imatinib therapy in $\mathrm{CML}$ and ALL

Assessment for ponatinib therapy in $\mathrm{CML}$; drives resistance to other BCR-ABL targeting inhibitors

Assessment for brentuximab vedotin therapy in Hodgkin lymphoma and anaplastic large cell lymphoma

Identifies patients not eligible for treatment with cetuximab and panitumumab

Assessment for crizotinib therapy in NSCLC

Assessment for dabrafenib, trametinib, and vemurafenib therapy in melanoma

Assessment for denileukin difitox therapy in cutaneous T-cell lymphoma

Assessment for ibritumomab tiuxetan therapy in B-cell NHL and follicular NHL, obinutuzumab and ofatumumab therapy in CLL, and rituximab therapy in $\mathrm{CLL}$ and $\mathrm{NHL}$

Assessment for imatinib therapy in gastrointestinal stromal tumors

Assessment for imatinib therapy in myelodysplastic/myeloproliferative disorders

Screening for cervical cancer

Monitoring of recurrence or progression of disease in ovarian cancer

Prediction of malignancy as part of the OVA-1 and ROMA tests and monitoring disease progression and response to therapy in ovarian cancer by itself

Prediction of malignancy in ovarian cancer as part of the OVA-1 test

Prediction of malignancy in ovarian cancer as part of the OVA-1 test

Prediction of malignancy in ovarian cancer as part of the OVA-1 test

Prediction of malignancy in ovarian cancer as part of the OVA-1 test

Monitoring disease progression in CRC

Risk assessment for development of disease in hepatocellular carcinoma

continued on page 384 
TABLE 2 continued from page 383

\section{Biomarker}

AFP

p63 protein

CA19-9

CA15-3

CA27.29

Prostate-specific antigen

Nuclear mitotic apparatus protein

Circulating tumor cells

Bladder tumor antigen

Thyroglobulin

Carcino-embryogenic antigen
Clinical use

Management of testicular cancer

Aids in differential diagnosis in prostate cancer

Monitoring disease status in pancreatic cancer

Monitoring response to therapy in breast cancer

Monitoring response to therapy in breast cancer

Prostate cancer diagnosis and monitoring; helps to discriminate between prostate cancer and benign disease

Diagnosis and monitoring of disease in bladder cancer

Prediction of cancer progression and survival in metastatic breast cancer, CRC, and castration-resistant prostate cancer

Monitoring of bladder cancer

Monitoring of thyroid cancer

Management and prognosis of cancer

ALL, acute lymphoblastic leukemia; CLL, chronic lymphocytic leukemia; CML, chronic myelogenous leukemia; CRC, colorectal cancer; EGFR, epidermal growth factor receptor; NHL, non-Hodgkin lymphoma; NSCLC, non-small-cell lung cancer

Adapted from http://www.fda.gov/drugs/scienceresearch/researchareas/pharmacogenetics/ucm083378.htm and Füzéry22

because they have the potential to allow for truly personalized cancer therapy. More than 40 oncology drugs that have been approved by the US Food and Drug Administration include biomarker information in their labeling and FDAapproved companion diagnostics have been developed to test for these biomarkers (Table 4).

Once again a prominent example is the HER2 protein, which predicts response to the HER2-targeted therapies trastzumab, pertuzumab, ado-trastuzumab emtansine, and lapatinib in patients with breast and gastric cancer. Likewise, overexpression of the epidermal growth factor receptor (EGFR) is required for response to EGFRtargeted therapies, such as cetuximab, and panitumumab in patients with colorectal cancer (CRC). A number of genetic mutations and chromosomal rearrangements also serve as predictive biomarkers, such as mutations in the $B R A F$ gene, which predict response to BRAF-targeted therapies, including vemurafenib. ${ }^{15}$

Predictive biomarkers are not only predictive of response, however, they can indicate that a patient will not respond to a particular therapy or that drug resistance has developed. Mutations in the KRAS gene generally indicate that a patient will not respond to EGFR-targeted therapy and as such these agents are only indicated in patients that screen negative for these mutations. Meanwhile, a specific mutation in the $B C R-A B L$ gene (T315I) in patients with chronic myelogenous leukemia is indicative of resistance to BCR-ABL targeting inhibitors. As a result of the identification of this biomarker in resistant patients, second-generation agents such as ponatinib have been developed that are effective even in the presence of this mutation. ${ }^{16}$

\section{Novel biomarker strategies}

In recent years, a number of novel types of cancer biomarker have been identified. Two in particular that are receiving significant attention are circulating tumor cells (CTCs) and circulating cell-free nucleic acids (cfNA). Although the former are approved as prognostic biomarkers in metastatic breast cancer, CRC and castration-resistant prostate cancer, cfNAs are still in early development.

CTCs are isolated tumor cells that have broken away from the site of disease in metastatic and/or primary cancers. Research has shown that CTCs could serve as valuable noninvasive prognostic biomarkers, dubbed a "liquid biopsy," offering insight into the formation of metastases at an earlier stage than do the current high-resolution imaging technologies. High basal levels of CTCs in patients with metastatic breast cancer, $\mathrm{CRC}$, and prostate cancer have been found to correlate with poor prognosis. ${ }^{17}$

Since CTCs are present in the range of only a few cells per millimeter of blood, even in patients with advanced metastatic cancer, the challenge of using CTCs is to identify them above a background of normal blood cells, so most methods for the identification of CTCs involve an initial enrichment step. ${ }^{18}$ Numerous methods have been developed that typically focus on isolating the CTCs on the basis of physical (eg, size) or biological (eg, presence of tumor-associated antigens) properties. Currently, the only FDA-approved method for CTC enrichment and identification is CellSearch, which uses magnetic particles coated with antibodies against the epithelial-specific antigen, epithelial cell adhesion molecule (EpCAM). However, many other methods are in clinical development. ${ }^{19}$ 
TABLE 3 Multigene expression panels

Test Manufacturer

Oval Aspira Labs

Risk of Ovarian

Malignancy Algorithm

(ROMA)

Fujirebio Diagnostics

\begin{tabular}{|c|c|c|}
\hline Oncotype DX & Genomic Health & $\begin{array}{l}\text { Biopsy-based RT-PCR assay that exam- } \\
\text { ines the expression of } 17 \text { genes (pros- } \\
\text { tate cancer), } 12 \text { genes (colon cancer) } \\
\text { or } 21 \text { genes (breast cancer) in tumor } \\
\text { tissue samples }\end{array}$ \\
\hline
\end{tabular}

Prolaris Myriad Genetics

$\begin{array}{cll}\text { MammaPrint } & \text { Agendia } & \begin{array}{l}\text { Analyzes the expression of } 70 \text { genes } \\ \text { in early-stage breast cancer tissue } \\ \text { samples }\end{array} \\ \text { TargetPrint } & \text { Agendia } & \begin{array}{l}\text { Microarray-based gene expres- } \\ \text { sion test used in breast cancer tissue } \\ \text { samples }\end{array}\end{array}$

\begin{tabular}{lll} 
BluePrint & Agendia & $\begin{array}{l}\text { Multigene profile used in breast can- } \\
\text { cer tissue samples }\end{array}$ \\
\hline Prosigna & $\begin{array}{l}\text { NM } \\
\text { Technologies }\end{array}$ & $\begin{array}{l}\text { Uses the PAM50 test to examine the } \\
\text { expression of } 50 \text { genes in breast can- } \\
\text { cer tissue samples }\end{array}$
\end{tabular}

$\begin{array}{lll}\text { CancerPRS Signal Genetics } & \begin{array}{l}\text { Examines the expression of } 163 \text { genes } \\ \text { (ColonPRS) or } 200 \text { genes (BreastPRS) } \\ \text { in tumor tissue samples }\end{array} \\ \text { Coloprint } & \text { Agendia } & \begin{array}{l}\text { Measures the expression of } 18 \text { genes } \\ \text { in colon cancer tissue samples }\end{array}\end{array}$

Genefx colon

Precision Therapeutics Microarray-based assay to examine

Oncodefender CRC

Everist Genomics
Examines the expression of 31 cell cycle progression genes in prostate cancer tissue samples the expression of 634 DNA transcripts in colon cancer tissue samples

Qualitative serum test that combines cancer tissue and HE4 tests in ovarian menopausal status

Qualitative serum test that examines ovarian cancer tissue samples; betamicroglobulin, CA-125, apolipoprotein $A 1$, prealbumin, and transferrin

Predicts cancer aggressiveness in prostate cancer, predicts risk of recurrence in patients with stage II/III colon cancer, guides treatment decisions in patients with ductal carcinoma in situ or invasive carcinoma

Identifies low-risk patients with prostate cancer and estimates risk of recurrence and guides therapeutic adjustment in patients with high-risk features after surgery

Identifies patients with high risk of distant recurrence and guides therapeutic decision-making

Offered in conjunction with MammaPrint to provide qualitative assessment of patient's estrogen receptor, progesterone receptor and HER2 expression levels

Separates breast tumors into molecular subtypes; basal-type, luminal-type, and HER2-type

Determines postsurgical risk of recurrence in postmenopausal women with stage I/II node-negative or stage II node-positive and hormone receptorpositive breast cancer

Predicts recurrence and overall survival in patients with stage II/III colon cancer (colon PRS) and identifies risk of recurrence for up to 10 years in breast cancer patients (BreastPRS)

Identifies risk of distant, local or regional relapse in patients with earlystage colorectal cancer

Assesses risk of recurrence within 5 years in patients with stage II colon cancer

Examines the expression of 5 genes in colorectal cancer tissue samples
Assesses risk of recurrence in stage I and II colorectal cancers and guides therapeutic decision-making
cfNAs, including DNA, RNA, and microRNA, are released from tumors into the blood stream when tumor cells undergo necrosis or apoptosis and may even be secreted by cancer cells. Altered levels of cfNAs are associated with increasing tumor burden and malignant progression. As with CTCs, cfNAs could also provide a liquid biopsy, and they are being evaluated as biomarkers of cancer progression and metastasis, as well as in cancer 
TABLE 4 Companion diagnostics approved by the US Food and Drug Administration

Device Manufacturer Description Clinical application

$\begin{array}{lll}\begin{array}{l}\text { Therascreen KRAS } \\ \text { RGQ PCR Kit }\end{array} & \text { Qiagen } & \begin{array}{l}\text { Real-time quantitative PCR assay that detects } \\ \text { seven somatic mutations in the KRAS gene } \\ \text { using DNA extracted from FFPE CRC tissue }\end{array} \\ \begin{array}{l}\text { DAKO EGFR } \\ \text { PharmDx Kit }\end{array} & \text { Dako } & \begin{array}{l}\text { IHC assay that identifies EGFR expression in } \\ \text { CRC patients }\end{array}\end{array}$

Identifies patients who are eligible for treatment with cetuximab and panitumumab on the basis of a 'no KRAS mutation' result

Identifies patients who are eligible for treatment with cetuximab and panitumumab on the basis of EGFR expression positivity

$\begin{array}{lll}\begin{array}{l}\text { Therascreen EGFR } \\ \text { RGQ PCR Kit }\end{array} & \text { Qiagen } & \begin{array}{l}\text { Real-time PCR assay for the qualitative } \\ \text { detection of exon 19 deletions and exon 21 } \\ \text { (L858R) substitution mutations in the EGFR } \\ \text { gene in DNA derived from FFPE NSCLC } \\ \text { tissue }\end{array} \\ \begin{array}{l}\text { Cobas EGFR } \\ \text { Mutation Kit }\end{array} & \begin{array}{c}\text { Roche } \\ \text { Molecular } \\ \text { Systems }\end{array} & \begin{array}{l}\text { Real-time PCR test for qualitative detection } \\ \text { of exon 19 deletions and exon 21 (L858) } \\ \text { substitution mutations of the EGFR gene in } \\ \text { DNA derived from FFPE NSCLC tumor tissue }\end{array} \\ \begin{array}{l}\text { INFORM HER2/ } \\ \text { NEU }\end{array} & \begin{array}{l}\text { Ventana } \\ \text { Medical } \\ \text { Systems }\end{array} & \begin{array}{l}\text { FISH DNA probe assay that determines the } \\ \text { qualitative presence of HER2/neu gene } \\ \text { amplification in FFPE breast tissue }\end{array}\end{array}$

$\begin{array}{lll}\text { PATHYVISION } & \text { Abbott } & \text { FISH assay designed to detect amplification } \\ \text { HER2 DNA Probe } & \text { Molecular } & \begin{array}{l}\text { of the HER2/neu gene in FFPE breast can- } \\ \text { cer tissue }\end{array}\end{array}$
Kit of the HER

Aids in the selection of patients with metastatic NSCLC who are eligible for treatment with erlotinib

Aids stratification of breast cancer patients according to risk for recurrence or diseaserelated death; used as an adjunct to existing clinical and pathologic information

Used as an adjunct to existing clinical and pathologic information currently used as prognostic factors in stage II, node-positive breast cancer; aids in prediction of disease-free and overall survival in patients with stage II, nodepositive breast cancer treated with adjuvant cyclophosphamide, doxorubicin, and 5-fluorouracil and in assessment of patients being considered for trastuzumab treatment

\begin{tabular}{|c|c|c|c|}
\hline $\begin{array}{l}\text { PATHWAY Anti- } \\
\text { HER2/NEU } \\
\text { (4B5) Rabbit } \\
\text { Monoclonal }\end{array}$ & $\begin{array}{l}\text { Ventana } \\
\text { Medical } \\
\text { Systems }\end{array}$ & $\begin{array}{l}\text { Mouse monoclonal antibody for semi-quanti- } \\
\text { tative detection of HER2/neu in FFPE breast } \\
\text { tissue }\end{array}$ & $\begin{array}{l}\text { Aids in the assessment of patients being consid- } \\
\text { ered for trastuzumab treatment }\end{array}$ \\
\hline
\end{tabular}
Antibody

$\begin{array}{lc}\text { INSITE HER2/ } & \text { Biogenics } \\ \text { NEU Kit } & \text { Laboratories }\end{array}$

Mouse monoclonal antibody (Clone C 1B 1 1) for the semi-quantitative localization of HER2/neu overexpression by light microscopy in FFPE breast tissue

$\begin{array}{lcl}\begin{array}{l}\text { SPOT-LIGHT HER2 } \\ \text { CISH Kit }\end{array} & \begin{array}{c}\text { Life } \\ \text { Technologies }\end{array} & \begin{array}{l}\text { CISH assay intended to quantitatively deter- } \\ \text { mine HER2 gene amplification in FFPE } \\ \text { breast cancer tissue }\end{array} \\ \begin{array}{l}\text { Bond Oracle } \\ \text { HER2 IHC System }\end{array} & \begin{array}{c}\text { Leica } \\ \text { Biosystems }\end{array} & \begin{array}{l}\text { Semi-quantitative IHC assay that determines } \\ \text { HER2 protein status in FFPE breast cancer } \\ \text { tissue }\end{array} \\ \begin{array}{l}\text { HER2 CISH } \\ \text { PharmDx Kit }\end{array} & \text { Dako } & \begin{array}{l}\text { Dual color CISH assay that quantitatively } \\ \text { determines HER2 gene status in FFPE breast } \\ \text { cancer tissue }\end{array} \\ & & \begin{array}{l}\text { INFORM HER2 } \\ \text { DUAL ISH DNA }\end{array} \\ \begin{array}{l}\text { Probe Cocktail } \\ \text { Ventana }\end{array} & \begin{array}{l}\text { Medical } \\ \text { Systems }\end{array} & \begin{array}{l}\text { Dual ISH DNA probe cocktail that deter- } \\ \text { mines HER2 gene status in FFPE breast can- } \\ \text { cer tissue }\end{array}\end{array}$

Aids in the assessment of patients being considered for trastuzumab treatment; adjunct to the clinicopathological information currently used for the management of breast cancer

Aids in the assessment of patients being considered for trastuzumab treatment

Aids in the assessment of breast cancer patients being considered for trastuzumab treatment

Aids in the assessment of patients being considered for trastuzumab treatment; adjunct to clinicopathologic information currently used for estimating prognosis in stage II, node-positive breast cancer patients

Aids in the assessment of patients for whom Aids in the assessment of patients for whom
trastuzumab treatment is being considered continued on next page 
TABLE 4 continued

\section{Device}

Manufacturer

$\begin{array}{ll}\text { HERCEPTEST } \quad \text { Dako } & \text { Semiquantitative IHC assay that identifies } \\ & \text { HER2 protein overexpression in FFPE breast } \\ & \text { and gastric cancer tissue }\end{array}$

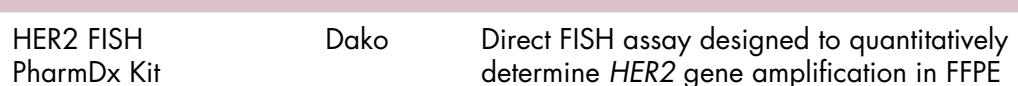

PharmDx Kit breast and gastric cancer tissue

\section{Clinical application}

Aids in the assessment of breast and gastric cancer patients being considered for trastuzumab treatment and for breast cancer patients being considered for pertuzumab or T-DMI treatment

Aids in assessment of breast and gastric cancer patients being considered for trastuzumab treatment and breast cancer patients being considered for pertuzumab or T-DM1 treatment; adjunct to clinicopathologic information currently used to estimate prognosis in stage II, node-positive breast cancer

\begin{tabular}{lcll} 
THXIDTM BRAF Kit & bioMérieux & $\begin{array}{l}\text { Real-time PCR test that qualitatively detects } \\
\text { the BRAF V6OOE/K mutations in DNA sam- } \\
\text { ples extracted from FFPE melanoma tissue }\end{array}$ & $\begin{array}{l}\text { Aids in selection of melanoma patients for treat- } \\
\text { ment with dabrafenib and trametinib }\end{array}$ \\
$\begin{array}{l}\text { Cobas } 4800 \\
\text { BRAF V600 } \\
\text { Mutation Test }\end{array}$ & $\begin{array}{c}\text { Roche } \\
\text { Solecular } \\
\text { Systems }\end{array}$ & $\begin{array}{l}\text { Real-time PCR assay designed to qualita- } \\
\text { tively detect the BRAF V600 mutation in } \\
\text { DNA extracted from FFPE melanoma tissue }\end{array}$ & $\begin{array}{l}\text { Aids in the selection of melanoma patients eli- } \\
\text { gible for treatment with vemurafenib }\end{array}$ \\
$\begin{array}{l}\text { DAKO c-KIT } \\
\text { PharmDx Kit }\end{array}$ & Dako & $\begin{array}{l}\text { IHC assay that identifies c-KIT protein } \\
\text { expression in patients with gastrointestinal } \\
\text { stromal tumors }\end{array}$ & $\begin{array}{l}\text { Allows differential diagnosis of GIST and iden- } \\
\text { tification of patients eligible for treatment with } \\
\text { imatinib }\end{array}$ \\
$\begin{array}{l}\text { VYSIS ALK Break } \\
\text { Apart FISH Probe } \\
\text { Kit }\end{array}$ & $\begin{array}{l}\text { Abbott } \\
\text { Molecular }\end{array}$ & $\begin{array}{l}\text { FISH assay that qualitatively detects ALK } \\
\text { gene rearrangements in FFPE NSCLC tissue } \\
\text { specimens }\end{array}$ & $\begin{array}{l}\text { Aids in identification of patients eligible for } \\
\text { treatment with crizotinib }\end{array}$ \\
\hline
\end{tabular}

$\mathrm{CISH}$, chromogenic in situ hybridization; CRC, colorectal cancer; EGFR, epidermal growth factor receptor; FFPE, formalin-fixed paraffin-embedded; FISH, fluorescent in situ hybridization; IHC, immunohistochemical; NSCLC, non-small-cell lung cancer; T-DM1, ado-trastuzumab emtansine

Adapted from: http://www.fda.gov/MedicalDevices/ProductsandMedicalProcedures/InVitroDiagnostics/ucm301431.htm

screening and monitoring therapeutic responses. ${ }^{20,21}$

\section{Challenges from bench to bedside}

Despite the recent boom in biomarker discovery, very few actually make it into clinical practice. There are several key phases of biomarker development and numerous challenges present at each stage that can prevent progression to the next. The most important factors in the clinical acceptance of a biomarker are the magnitude of its clinical value and the quality of clinical trial data. As such, these are areas where biomarker development typically runs into difficulty as researchers face hurdles in identifying the true clinical utility or lack well-controlled trial data (Figure 2).

The effective clinical validation of a biomarker is extremely complex, time consuming, and expensive. Because biomarkers were initially often identified as a byproduct of research, one of the most significant confounding issues in their effective translation into the clinic was a limited understanding of optimum analytical, diagnostic and regulatory requirements for biomarker validation. With the evolution of the biomarker field into a bona fide area of research this has begun to change. Researchers in the field are developing a framework for effective biomarker development that includes the implementation of clinical guide-
Why biomarkers fail to reach the clinic

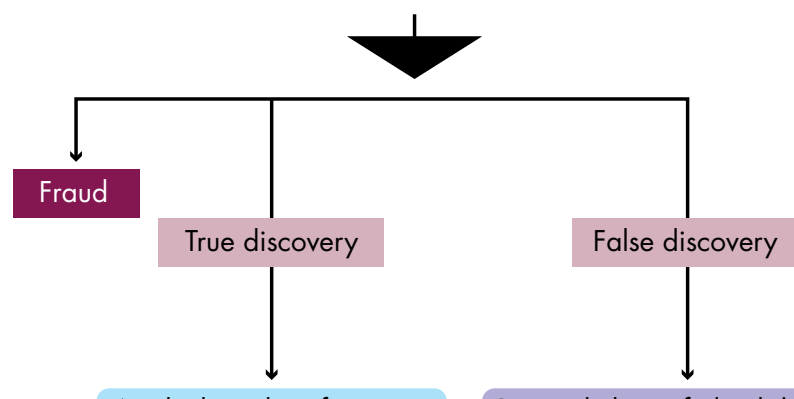

Weak clinical performance

Original claims fail validation
Low specificity

- Low sensitivity

- low prognostic/predictive value

- Information not necessary for clinical decision-making
Shortcomings

- Pre-analytical

- Analytical

- Post-analytical

n Bioinformatic
FIGURE 2 Summary of the reasons for biomarker failure to reach the clinic

Adapted with permission from Diamandis EP. BMC Medicine. 2012;10:87. 
lines (eg, REMARK [Reporting Recommendations for Tumor Marker Prognostic Studies] guidelines). ${ }^{15,22,23}$

The road from bench to bedside for cancer biomarkers is long and arduous, but new and exciting discoveries continue to be made. As researchers begin to understand the challenges faced and develop strategies to overcome these barriers, cancer biomarkers may begin to meet their full potential in personalized cancer therapy.

\section{References}

1. American Cancer Society. Cancer Facts and Figures 2014. http:// www.cancer.org/acs/groups/content/@research/documents/webcontent/acspc-042151.pdf. Accessed August 28, 2014.

2. Biomarkers Definitions Working Group. Biomarkers and surrogate endpoints: preferred definitions and conceptual framework. Clin Pharmacol Ther. 2001;69:89-95.

3. Jones HB. On a new substance occurring in the urine of a patients with mollities ossium. Phil Trans R Soc Lond. 1848;138:55-62.

4. Partin AW, Kattan MW, Subong EN, et al. Combination of prostate-specific antigen, clinical stage, and Gleason score to predict pathological stage of localized prostate cancer: a multi-institutional update. JAMA. 1997;277:1445-1451.

5. Ito K, Fujizuka Y, Ishikura K, et al. Next-generation prostate-specific antigen test: precursor form of prostate-specific antigen. Int J Clin Oncol. 2014: Epub ahead of print.

6. Varadhachary GR, Raber MN. Cancer of unknown primary site. N Engl J Med. 2014;371:757-765.

7. Kerr SE, Schnabel CA, Sullivan PS, et al. Multisite validation study to determine performance characteristics of a 92-gene molecular cancer classifier. Clin Cancer Res. 2012;18:3952-3960.

8. Owens MA, Horten BC, Da Silva MM. HER2 amplification ratios by fluorescence in situ hybridization and correlation with immunohistochemistry in a cohort of 6556 breast cancer tissues. Clin Breast Cancer. 2004;5:63-69.

9. Slamon DJ, Clark GM, Wong SG, et al. Human breast cancer: correlation of relapse and survival with amplification of the HER-2/neu oncogene. Science. 1987;235:177-82.

10. Yaziji H, Goldstein LC, Barry TS, et al. HER-2 testing in breast cancer using parallel tissue-based methods. JAMA 2004;291:1972-7.
11. Genomic Health. What do major guidelines say about the Oncotype DX assay? http://breast-cancer.oncotypedx.com/en-US/ProfessionalInvasive/WhatIsTheOncotypeDXBreastCancerTest/WhatDoMajorGuidelinesSayAboutTheTest.aspx . Released 2014. Accessed August 28,2014

12. Fan C, Oh DS, Wessels L, et al. Concordance among geneexpression-based predictors for breast cancer. N Engl J Med. 2006;355:560-569.

13. Dowsett M, Sestak I, Lopez-Knowles E, et al. Comparison of PAM50 risk of recurrence score with oncotype DX and IHC4 for predicting risk of distant recurrence after endocrine therapy. J Clin Oncol. 2013;31:2783-2790.

14. Gnant M, Dowsett M, Filipits $M$, et al. Identifying clinically relevant prognostic subgroups in node-positive postmenopausal HR+ early breast cancer patients treated with endocrine therapy: A combined analysis of 2,485 patients from ABCSG-8 and ATAC using the PAM50 risk of recurrence (ROR) score and intrinsic subtype [ASCO abstract 506]. J Clin Oncol. 31:2013(suppl).

15. Bailey AM, Mao Y, Zeng J, et al. Implementation of biomarker-driven cancer therapy: existing tools and remaining gaps. Discov Med. 2014;17:101-114

16. Bose P, Park H, Al-Khafaji J, et al. Strategies to circumvent the T315I gatekeeper mutation in the Bcr-Abl tyrosine kinase. Leukemia Res Rep. 2013;2:18-20.

17. Gorges TM, Pantel K. Circulating tumor cells as therapy-related biomarkers in cancer patients. Cancer Immunol Immunother. 2013;62:931-939.

18. Fischer AH. Circulating tumor cells: seeing is believing. Arch Pathol Lab Med. 2009;133:1367-1369.

19. Arya SK, Lim B, Rahman AR. Enrichment, detection and clinical significance of circulating tumor cells. Lab Chip. 2013;13:1995-2027.

20. Schwarzenbach H, Hoon DBS, Pantel K. Cell-free nucleic acids as biomarkers in cancer patients. Nat Rev Cancer. 2011;11:426-437.

21. Schwarzenbach H, Nishida N, Calin GA, et al. Clinical relevance of circulating cell-free microRNAs in cancer. Nat Rev Clin Oncol. 2014;11:145-56.

22. Füzéry AK, Levin J, Chan MM, et al. Translation of proteomic biomarkers into FDA approved cancer diagnostics: issues and challenges. Clinical Proteomics. 2013;10:13.

23. McShane LM, Altman DG, Sauerbrei W, et al. Reporting recommendations for tumor marker prognostic studies. J Clin Oncol. 2005;23:9067-9072 